\begin{tabular}{|c|c|}
\hline Title & Time related change evaluation of the cerebrospinal fluid using postmortem CT \\
\hline Author(s) & Morikawa, Kohei; Hyodoh, Hideki; Matoba, Kotaro; Mizuo, Keisuke; Okazaki, Shunichiro; W atanabe, Satoshi \\
\hline Citation & $\begin{array}{l}\text { Legal medicine, 22, 30-35 } \\
\text { https://doi.org/10.1016/.legal med.2016.07.010 }\end{array}$ \\
\hline Issue Date & 2016-09 \\
\hline Doc URL & http:/hdl .handle.net/2115/67077 \\
\hline Rights & $\begin{array}{l}\text { @ 2016. This manuscript version is made available under the CC-BY-NC-ND } 4.0 \text { license } \\
\text { http://creativecommons.org/icenses/by-nc-nd/4.0/ }\end{array}$ \\
\hline Rights(URL) & http://creativecommons.org/icenses/by-nc-nd/4.0/ \\
\hline Type & article (author version) \\
\hline File Information & LegMed22_30.pdf \\
\hline
\end{tabular}

Instructions for use 
Title: Time-related change evaluation of the cerebrospinal fluid using postmortem CT

Kohei Morikawa

Hideki Hyodoh*

Kotaro Matoba**

Keisuke Mizuo

Shunichiro Okazaki,

Satoshi Watanabe

Dept. Legal Medicine, Sapporo Medical University School of Medicine

${ }^{*}$ Center for Cause of Death Investigation, Hokkaido University, Graduate School of Medicine

**Dept. Forensic Medicine, Hokkaido University, Graduate School of Medicine

Corresponding author

Hideki Hyodoh, MD, PhD

Center for Cause of Death Investigation,

Hokkaido University, Graduate School of Medicine

N17 W7 Kita-ku Sapporo, 060-8638, JAPAN

e-mail: hyodoh@med.hokudai.ac.jp

phone: +81-11-706-5905

fax: +81-11-706-7860

Key words: postmortem CT, cerebrospinal fluid, postmortem interval, postmortem change, forensic radiology 
Highlights

- We retrospectively evaluated the cerebrospinal fluid (CSF) CT density to compare the postmortem intervals.

- Postmortem $3^{\text {rd }}$ day was the earliest increased CSF density compared to the day 1 and day 1.5 , statistically.

- Postmortem $7^{\text {th }}$ day showed increased CSF density compared to the early postmortem days (up to the $3^{\text {rd }}$ day).

- There was no significant correlation between CSF density and estimated postmortem interval. 


\section{Time-related change evaluation of the cerebrospinal fluid using postmortem CT}

\section{Abstract}

Purpose:

We retrospectively evaluated the cerebro-spinal fluid (CSF) CT density at the lateral ventricle to compare the postmortem intervals in cadavers.

Materials and Methods:

The number of cadavers enrolled in this study was 189 (male 120, female 69). According to the estimated postmortem time, the cadavers were divided into 13 groups (postmortem day $0.5,1,1.5,2,2.5,3,4,5,7,10,14,21,30$ ), and were also re-grouped into 3 groups according to the postmortem time-width: group A (postmortem day 0.5 - 2.5), group B (day $3-7$ ), and group C (day 10 - 30). Comparisons between the CSF density and estimated postmortem time were also analyzed.

Results:

The CSF density was around $20 \mathrm{HU}$ up to day 2.5 , and it increased gradually after day 3 . Day 3 and 4 presented higher CSF density than day 1 and $1.5(\mathrm{p}<0.05)$. Day 7 presented higher CSF density than day $3(\mathrm{p}<0.05)$.

According to the postmortem time-width, the CSF density increased with postmortem time $(\mathrm{p}<0.05)$.

The simple linear regression equations presented negative correlation between CSF density and estimated postmortem time, and $\mathrm{R}^{2}$ was 0.119 .

Conclusion:

The CSF density increased, but not linearly, according to the postmortem time, and the $3^{\text {rd }}$ postmortem day was the earliest time allowing the difference to be detected. The CSF density needs further evaluation to enable estimation of the postmortem time. 


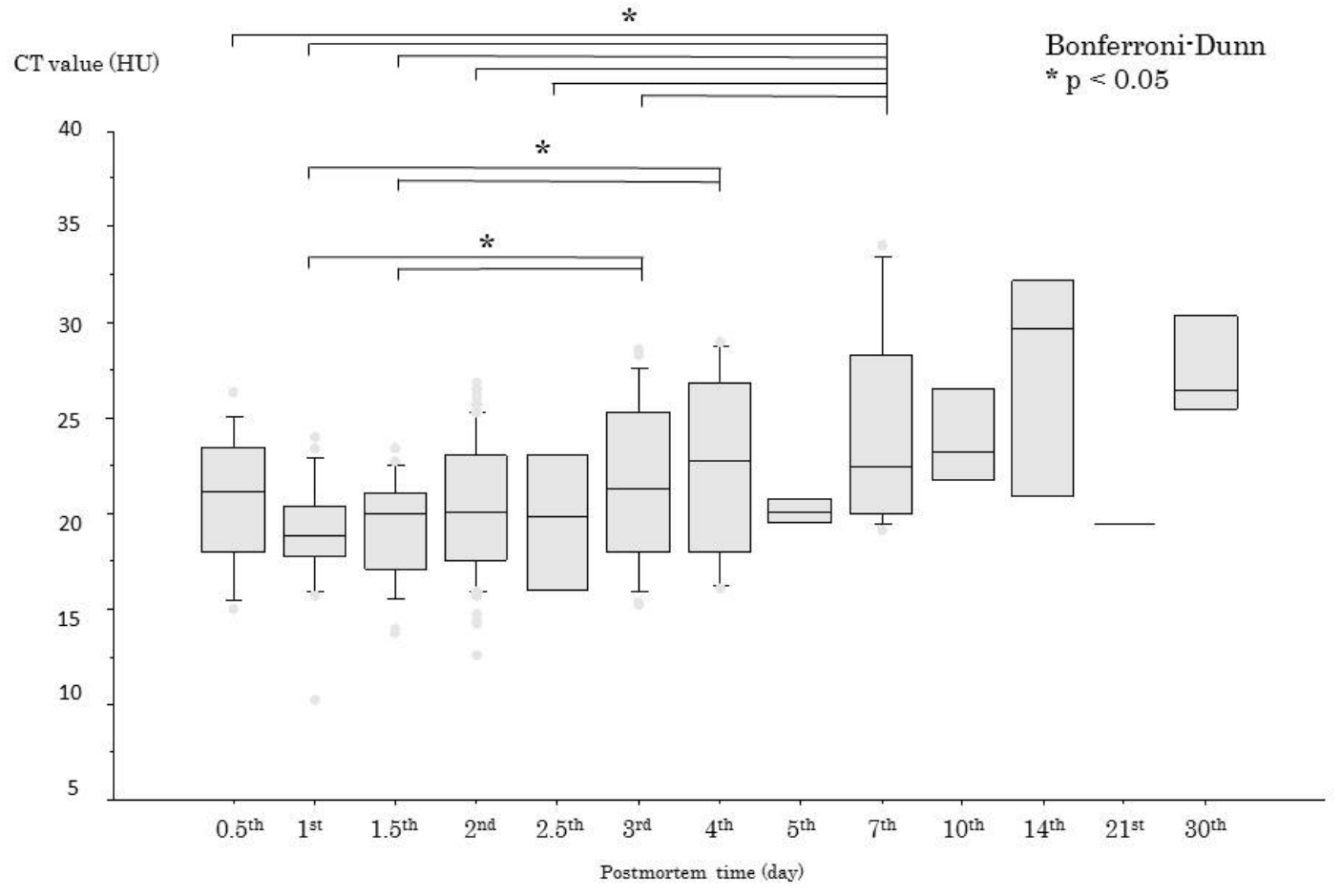

CSF CT value along the postmortem period

The short postmortem period showed around $20 \mathrm{HU}$ in CSF density, and it is gradually increased along with postmortem intervals. In statistical evaluation, postmortem day 3 was the earliest increased CSF density compared to day 1 and 1.5. 


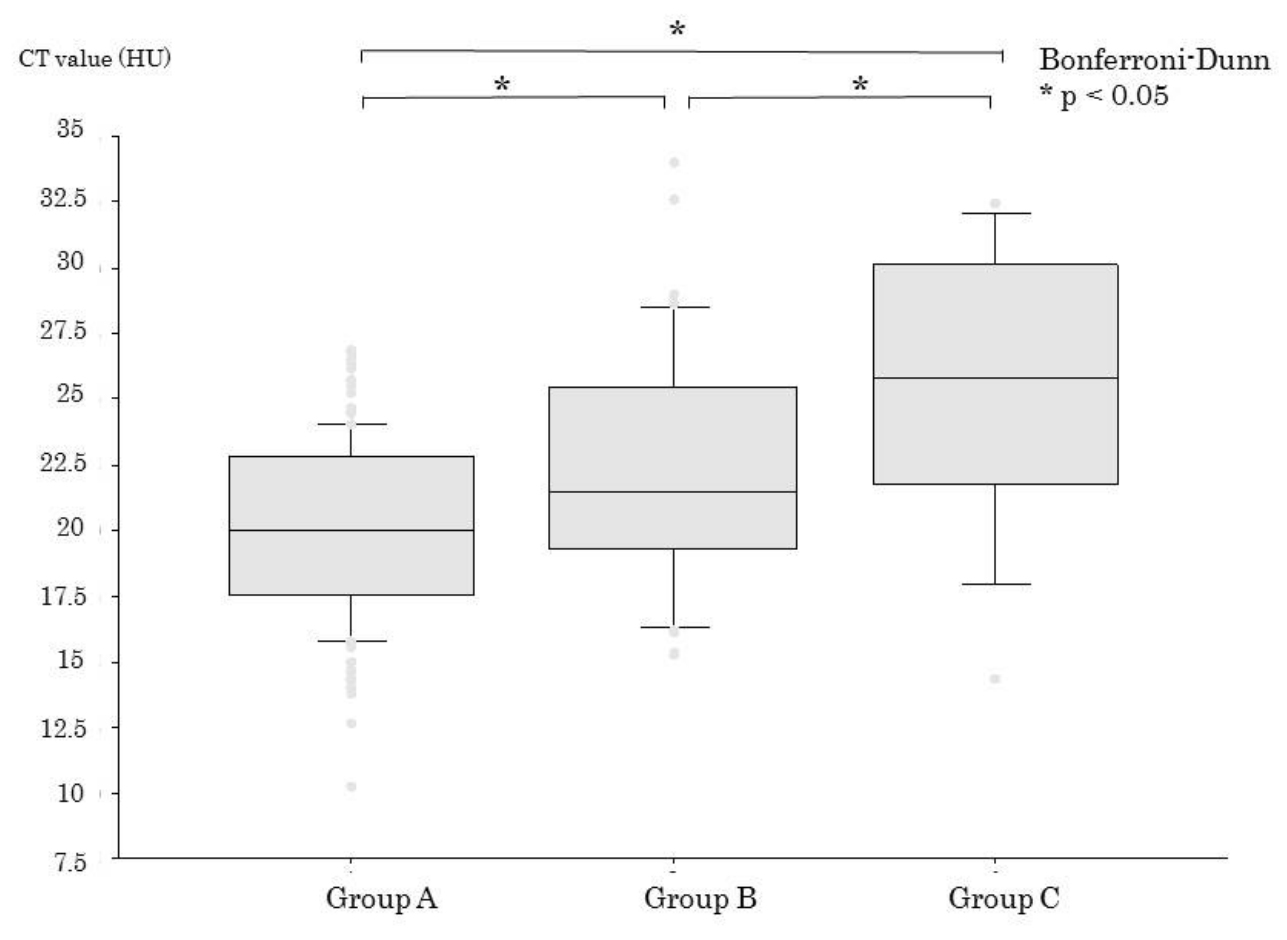

CSF CT value compared with the postmortem time-width

The CSF density shows an increase along with postmortem time-width, which is statistically significant.

Postmortem period:

Group A: up to day 2.5

Group B: day 3 to 7

Group C: beyond day 7 


\section{Background}

One of the recent topics attracting interest in the field of legal medicine is postmortem CT imaging [1-3], and one of the reasons for this attraction is its objectivity [4, 5]. Postmortem CT images have the advantage of being able to provide objective information when required in cases such as personal identification $[6,7]$, and injury [8-12]. In addition, postmortem CT images have been used to investigate the cause of death $[13,14]$. Thali et al. have reported on postmortem CT images combined with 3D surface recording, so called Virtopsy, and the postmortem image has been established as one of the important documents in the regional medical / social system [1, 15].

With increasing use and experience of postmortem CT examination, unknown findings have been detected on postmortem CT images [16, 17], so that it is important to evaluate specific postmortem change as it relates to pathological condition [18]. In addition, some postmortem CT image changes presented similarly to specific pathological lesions, so that it is important to differentiate disease-oriented pathological change from postmortem change [18, 19]. To address these issues and facilitate the use of postmortem CT in investigating the cause of death, it will be necessary to understand both the normal postmortem changes, and how to differentiate them from changes related to other causes.

Repeated studies on CT imaging have been reported which demonstrate the time-related postmortem change in brain, especially the lateral ventricle density in early postmortem period [20, 21]. But these reports covered only the short postmortem period, and longer postmortem interval evaluation is necessary in order to understand the time-related change in practical forensic radiology investigation.

In this study, we retrospectively evaluated the cerebrospinal fluid (CSF) CT density at the lateral ventricle to compare the postmortem intervals in cadavers. 


\section{Materials and Methods}

This study was approved by the ethics committees of our institutions.

Postmortem CT images obtained prior to full autopsy from January 2012 to November 2015 were utilized in the study. The following exclusion criteria were used: pediatric (younger than 20), small ventricle size (less than region-of-interest (ROI) size), cause of death was hypothermia or intra-cranial bleeding, containing intra-cranial gas, part of brain missing, and ambiguous postmortem interval time.

Imaging protocol

All cadavers were examined by postmortem CT prior to the full autopsy. The whole body scan was evaluated using a 64-slice multidetector CT scanner (Aquilion CX, Toshiba, Japan). The parameters from neck to head part were as follows: $120 \mathrm{kV}$, $300 \mathrm{~mA}, 1.0$ s/rotation, pitch factor 0.641 , configuration $0.5 \times 32$, reconstruction 0.5 $\mathrm{mm}$, MPR (multiplanar reconstruction) image reconstruction $5 \mathrm{~mm}$ in axial, sagittal, and coronal sections.

Imaging analysis

All data sets were transferred to an image server in Digital Imaging and Communication in Medicine (so called DICOM) format and the 3 ROIs, at the lateral ventricle excluding the choroid plexus or artifact, were positioned to measure the CSF density using OsiriX (App v.3.9.4). The CSF density was calculated from the average of the 3 measured ROIs and the standard deviation (SD) was also calculated (Fig 1).

Estimated postmortem time

Postmortem time was evaluated according to the results of the full autopsy and the information on the cadaver's circumstances. When the postmortem time was estimated with time width, the maximum period was used to estimate postmortem time.

\section{Statistical analysis}

To evaluate the time-related CSF density change course, the full number of cadavers was divided into groups according to the postmortem time: such as day 0.5, $1,1.5,2,2.5,3,4,5,7$, and $>7$. In addition, the cadavers were divided into 3 groups using the concept of postmortem time-width: up to day 2.5 (group A), day 3 to 7 (group B), and beyond day 7 (group C). We used StatView (SAS Institute Inc., North 
Carolina, USA, Version 5.0) software with a Bonferroni/Dunn study. Differences with $\mathrm{p}<0.05$ were considered statistically significant. The collected data were also analyzed with a Spearman's rank correlation test for the comparison between the CSF density and estimated postmortem time. 
Results

The cadavers evaluated by postmortem CT prior to full autopsy numbered 391 . According to the exclusion criteria, 202 cadavers were excluded: less than 20 year-old $(n=25)$, ambiguousness of lateral ventricles $(n=5)$, hypothermia $(n=10)$, intra-cranial bleeding $(n=26)$, intra-cranial gas $(n=109)$, lost information of head part $(n=6)$, and undefined postmortem-time $(n=21)$. Eventually, 189 cadavers (male 120, female 69) were enrolled in this study.

The causes of death were as follows; drowning $(\mathrm{n}=31)$, sudden cardiac death $(\mathrm{n}=$ $23)$, asphyxia $(n=18)$, carbon monoxide poisoning $(n=10)$, multi-organ failure $(n=$ $7)$, blood loss $(n=5)$, sepsis $(n=4)$, burn $(n=4)$, drug poisoning $(n=4)$, pulmonary artery embolization $(n=2)$, crash syndrome $(n=2)$, electrocution $(n=2)$, peritonitis $(n=1)$, ketoacidosis $(n=1)$, cardiac tamponade $(n=1)$, cancer $(n=1)$, hanging $(n=$ $1)$, brain infarction $(n=1)$, malnutrition $(n=1)$, renal failure $(n=1)$, and unknown $(\mathrm{n}=69)$.

Postmortem times were as follows: day $0.5(\mathrm{n}=12)$, day $1(\mathrm{n}=17)$, day $1.5(\mathrm{n}=24)$, day $2(\mathrm{n}=80)$, day $2.5(\mathrm{n}=4)$, day $3(\mathrm{n}=22)$, day $4(\mathrm{n}=7)$, day $5(\mathrm{n}=2)$, day $7(\mathrm{n}=$ $9)$, day $10(\mathrm{n}=4)$, day $14(\mathrm{n}=4)$, day $21(\mathrm{n}=1)$, and day $30(\mathrm{n}=3)$. The 3 groups of the postmortem time-width were group A day $0.5-2.5$ (mean 1.7 days), group B day 3 - 7 (4.2 days), and group $\mathrm{C}$ day 10 - 30 (17.3 days). On examining basic case profiles, no significant differences were found among the postmortem times, nor among the groups $\mathrm{A}, \mathrm{B}$, and $\mathrm{C}$.

\section{CSF CT value}

The measurements of CSF density are shown in Table 1. The CSF density was around $20 \mathrm{HU}$ up to day 2.5, and it increased gradually after day 3. Day 5, 10, 14, 21, and 30 were excluded from statistical evaluation because of insufficient numbers. Using Bonferroni-Dunn test, day 3 and day 4 presented higher CSF density than day 1 , and day $1.5(\mathrm{p}<0.05)$, and day 7 presented higher CSF density than day 0.5, 1 , 1.5, 2, 2.5, and day $3(\mathrm{p}<0.05)$ (Fig 2) (Table 2).

According to the postmortem time-width, the mean CT values of CSF density were $20.0 \pm 3.3$ in group A, $22.0 \pm 4.2$ in group B, and $26.5 \pm 5.9$ in group C (Fig 3, Table 3). There were statistical differences among the three groups, thus the CSF density was increasing with the postmortem intervals. 
The simple linear regression equations presented negative correlation between CSF density and estimated postmortem time, and $R^{2}$ was 0.119 . The linear equation formula for postmortem time was $\mathrm{Y}=19.804+0.324 * \mathrm{X}$. 


\section{Discussion}

Postmortem CT findings have been reported showing changes with the postmortem intervals in vascular diameters [22, 23], lung appearance [24, 25], and pleural effusion [18, 26]. In this study, the CSF density at the lateral ventricles showed an increase with postmortem time, and this was concordant with previous reports [20, 21]. In addition, according to postmortem time-width, the CSF density exhibited a statistically significant increase along with postmortem time. This is the first report of a statistical increase in CSF.

The mechanisms of increasing CSF density are still under evaluation. Hasegawa et al. [21] reported the possibility of decomposition of CSF protein and / or the ependymal layer, CSF condensation while a swelling brain exerts pressure on the ventricles leading to shrinkage, and inflow of protein-like substances from the periventricular brain tissues to the CSF. The increasing X-ray absorption leads to the increasing CT value, so that the CSF must be increasing its density along with postmortem time. Further study will be needed to evaluate the pathological change of the ependymal layer and / or periventricular brain tissue affect increasing CT density with the postmortem time.

Koopmanschap et al. [20] reported that the correlation between density and postmortem interval showed a significant correlation and the maximum postmortem interval can be estimated by a linear correlation in early postmortem period. Hasegawa et al. [21] also reported a linear equation formula relating postmortem time and CSF CT density. They used cadavers with confirmed time of death and examined within the early postmortem time. From our results, there was no significant linear correlation between CSF density and estimated postmortem time. It was thought that the postmortem times covered too wide a time range, and in addition, environmental factors (temperature, humidity, and wind) might affect the postmortem change. Furthermore, the standard deviation of CSF density was large and there was overlap between postmortem times, which made it difficult to estimate the postmortem time using CSF CT density.

In this study, the difference in CSF density over the postmortem interval was within 10 Hounsfield Units (HU), and it would seem difficult to differentiate it without ROI measurement. To put it another way, the CSF density showed no big difference over postmortem time. If we selected a suitable threshold, it could be 
used to indicate a physiological condition (such as intra-ventricle bleeding) based on the CSF density. In this investigation, the CSF density reached a maximum of 34 $\mathrm{HU}$, so that a value of more than $35 \mathrm{HU}$ may present the possibility of a pathological condition. On the other hand, blood leakage (transudation) to the sub-arachnoid space has been reported in postmortem change [27]. If this phenomenon may affect the lateral ventricle, the CSF density evaluation would be useless. It will be necessary to evaluate if and how blood leakage (transudation) occurs during the postmortem time into the lateral ventricle.

We used exclusion criteria such as pediatrics, small ventricle size, hypothermic death, intra-cranial bleeding, intra-cranial gas, incomplete brain, and unknown postmortem interval time. A small ventricle would make it difficult to measure CSF density using ROI. Hypothermia has been reported to affect the postmortem change [18, 24, 28, 29]. Intra-cranial bleeding and gas would affect the CSF density directly, and make it difficult to evaluate the normal postmortem CSF density change. Either brain incompleteness or unknown postmortem interval time would make it impossible to evaluate the CSF density change according to postmortem time. In the normal postmortem change, putrefaction might also affect the cadaver and produce putrefaction gas [30, 31]. In this study, CSF density could be evaluated for long postmortem time in 12 cases (beyond day 10). A cadaver which was not a hypothermic death might be placed low temperature conditions so that it would retain its postmortem condition without deterioration. Therefore, to observe the true CSF density change according to the postmortem interval, it would be necessary to control the cadaver's environmental conditions, especially the temperature.

\section{Limitations}

Several limitations may be listed concerning this study. First, we used the same CT equipment with the same protocol throughout, but if different CT equipment and / or a different protocol was used, the CSF density might result in a different CT number. Second, the 3 ROI measurements were taken by one operator to minimize the operator dependency. But if automatic ROI setting was used for the measurements, more objective data could be obtained for evaluating the CSF density change with the postmortem time. Third, we used the postmortem time from the evaluation of the autopsy findings, which might contain some error range. 


\section{Conclusion}

The CSF density was increasing, but not linearly, according to the postmortem time. Compared with the early postmortem time, the $3^{\text {rd }}$ postmortem day was the earliest time to show any increase, and the $7^{\text {th }}$ postmortem day was the first to show a statistically significant difference. Because much overlap of CSF density was evident, it was difficult to estimate the postmortem time based on CSF density. 


\section{References}

[1] M.J. Thali, K. Yen, W. Schweitzer, P. Vock, C. Boesch, C. Ozdoba, G. Schroth, M. Ith, M. Sonnenschein, T. Doernhoefer, E. Scheurer, T. Plattner, R. Dirnhofer, Virtopsy, a new imaging horizon in forensic pathology: virtual autopsy by postmortem multislice computed tomography (MSCT) and magnetic resonance imaging (MRI)--a feasibility study, J Forensic Sci 48(2) (2003) 386-403.

[2] S. Shiotani, M. Kohno, N. Ohashi, K. Yamazaki, Y. Itai, Postmortem intravascular high-density fluid level (hypostasis): CT findings, J Comput Assist Tomogr 26(6) (2002) 892-3.

[3] N. Takahashi, T. Higuchi, M. Shiotani, Y. Hirose, H. Shibuya, H. Yamanouchi, H. Hashidate, K. Funayama, The effectiveness of postmortem multidetector computed tomography in the detection of fatal findings related to cause of non-traumatic death in the emergency department, Eur Radiol 22(1) (2012) 152-60.

[4] E. Aghayev, L. Staub, R. Dirnhofer, T. Ambrose, C. Jackowski, K. Yen, S. Bolliger, A. Christe, C. Roeder, M. Aebi, M.J. Thali, Virtopsy - the concept of a centralized database in forensic medicine for analysis and comparison of radiological and autopsy data, J Forensic Leg Med 15(3) (2008) 135-40.

[5] M.J. Thali, M. Braun, U. Buck, E. Aghayev, C. Jackowski, P. Vock, M. Sonnenschein, R. Dirnhofer, VIRTOPSY--scientific documentation, reconstruction and animation in forensic: individual and real 3D data based geo-metric approach including optical body/object surface and radiological CT/MRI scanning, J Forensic Sci 50(2) (2005) 428-42.

[6] D. Lorkiewicz-Muszynska, W. Kociemba, C. Zaba, M. Labecka, M. Koralewska-Kordel, M. Abreu-Glowacka, A. Przystanska, The conclusive role of postmortem computed tomography (CT) of the skull and computer-assisted superimposition in identification of an unknown body, Int J Legal Med 127(3) (2013) 653-60.

[7] A. Sakuma, M. Ishii, S. Yamamoto, R. Shimofusa, K. Kobayashi, H. Motani, M. Hayakawa, D. Yajima, H. Takeichi, H. Iwase, Application of postmortem 3D-CT facial reconstruction for personal identification, J Forensic Sci 55(6) (2010) 1624-9. [8] T. Okuda, S. Shiotani, H. Hayakawa, K. Kikuchi, T. Kobayashi, Y. Ohno, A case of fatal cervical discoligamentous hyperextension injury without fracture: correlation of postmortem imaging and autopsy findings, Forensic Sci Int 225(1-3) (2013) 71-4.

[9] K.M. Yang, M. Lynch, C. O'Donnell, "Buckle" rib fracture: an artifact following cardio-pulmonary resuscitation detected on postmortem CT, Leg Med (Tokyo) 13(5) 
(2011) 233-9.

[10] G. Ampanozi, T.D. Ruder, U. Preiss, K. Aschenbroich, T. Germerott, L. Filograna, M.J. Thali, Virtopsy: CT and MR imaging of a fatal head injury caused by a hatchet: A case report, Leg Med (Tokyo) 12(5) (2010) 238-41.

[11] S. Shiotani, M. Shiigai, Y. Ueno, N. Sakamoto, S. Atake, M. Kohno, M. Suzuki, H. Kimura, K. Kikuchi, H. Hayakawa, Postmortem computed tomography findings as evidence of traffic accident-related fatal injury, Radiat Med 26(5) (2008) 253-60.

[12] E. Aghayev, M. Thali, C. Jackowski, M. Sonnenschein, K. Yen, P. Vock, R. Dirnhofer, Virtopsy--fatal motor vehicle accident with head injury, J Forensic Sci 49(4) (2004) 809-13.

[13] Y. Makino, S. Yamamoto, S. Shiotani, H. Hayakawa, H. Fujimoto, H. Yokota, T. Horikoshi, H. Iwase, T. Uno, Can ruptured abdominal aortic aneurysm be accurately diagnosed as the cause of death without postmortem computed tomography when autopsies cannot be performed?, Forensic Sci Int 249 (2015) 107-11.

[14] N. Takahashi, T. Higuchi, M. Shiotani, H. Maeda, O. Sasaki, Multiple lung tumors as the cause of death in a patient with subarachnoid hemorrhage: postmortem computed tomography study, Jpn J Radiol 27(8) (2009) 316-9.

[15] S.A. Bolliger, M.J. Thali, S. Ross, U. Buck, S. Naether, P. Vock, Virtual autopsy using imaging: bridging radiologic and forensic sciences. A review of the Virtopsy and similar projects, Eur Radiol 18(2) (2008) 273-82.

[16] M. Sugimoto, H. Hyodoh, M. Rokukawa, A. Kanazawa, R. Murakami, J. Shimizu, S. Okazaki, K. Mizuo, S. Watanabe, Freezing effect on brain density in postmortem CT, Leg Med (Tokyo) 18 (2016) 62-5.

[17] A. Kanazawa, H. Hyodoh, S. Watanabe, M. Fukuda, M. Baba, S. Okazaki, K. Mizuo, E. Hayashi, H. Inoue, New pitfalls of high-density postmortem computed tomography, Leg Med (Tokyo) 16(5) (2014) 297-9.

[18] H. Hyodoh, J. Shimizu, M. Rokukawa, S. Okazaki, K. Mizuo, S. Watanabe, Postmortem computed tomography findings in the thorax - Experimental evaluation, Leg Med (Tokyo) 19 (2016) 96-100.

[19] N. Takahashi, C. Satou, T. Higuchi, M. Shiotani, H. Maeda, Y. Hirose, Quantitative analysis of brain edema and swelling on early postmortem computed tomography: comparison with antemortem computed tomography, Jpn J Radiol 28(5) (2010) 349-54.

[20] D.H. Koopmanschap, A.R. Bayat, B. Kubat, H.M. de Bakker, M.W. Prokop, W.M. Klein, The radiodensity of cerebrospinal fluid and vitreous humor as indicator of the 
time since death, Forensic Sci Med Pathol (2016).

[21] I. Hasegawa, A. Shimizu, A. Saito, H. Suzuki, H. Vogel, K. Puschel, A. Heinemann, Evaluation of post-mortem lateral cerebral ventricle changes using sequential scans during post-mortem computed tomography, Int J Legal Med (2016).

[22] N. Takahashi, T. Higuchi, Y. Hirose, H. Yamanouchi, H. Takatsuka, K. Funayama, Changes in aortic shape and diameters after death: comparison of early postmortem computed tomography with antemortem computed tomography, Forensic Sci Int 225(1-3) (2013) 27-31.

[23] H. Hyodoh, T. Sato, M. Onodera, H. Washio, T. Hasegawa, M. Hatakenaka, Vascular measurement changes observed using postmortem computed tomography, Jpn J Radiol 30(10) (2012) 840-5.

[24] H. Hyodoh, S. Watanabe, R. Katada, K. Hyodoh, H. Matsumoto, Postmortem computed tomography lung findings in fatal of hypothermia, Forensic Sci Int 231(1-3) (2013) 190-4.

[25] S. Shiotani, T. Kobayashi, H. Hayakawa, K. Kikuchi, M. Kohno, Postmortem pulmonary edema: a comparison between immediate and delayed postmortem computed tomography, Leg Med (Tokyo) 13(3) (2011) 151-5.

[26] H. Hyodoh, J. Shimizu, S. Watanabe, S. Okazaki, K. Mizuo, H. Inoue, Time-related course of pleural space fluid collection and pulmonary aeration on postmortem computed tomography (PMCT), Leg Med (Tokyo) 17(4) (2015) 221-5.

[27] L. Xiang, G. Zhou, P. Su, S. Xia, B. Han, Y. Wang, T. Zhang, Could postmortem hemorrhage occur in the brain?: a preliminary study on the establishment and investigation of postmortem hypostatic hemorrhage using rabbit models, Am $\mathrm{J}$ Forensic Med Pathol 34(2) (2013) 147-9.

[28] N. Sogawa, T. Michiue, T. Ishikawa, O. Kawamoto, S. Oritani, H. Maeda, Postmortem volumetric CT data analysis of pulmonary air/gas content with regard to the cause of death for investigating terminal respiratory function in forensic autopsy, Forensic Sci Int 241 (2014) 112-7.

[29] Y. Kawasumi, N. Onozuka, A. Kakizaki, A. Usui, Y. Hosokai, M. Sato, H. Saito, T. Ishibashi, Y. Hayashizaki, M. Funayama, Hypothermic death: possibility of diagnosis by post-mortem computed tomography, Eur J Radiol 82(2) (2013) 361-5.

[30] A. Christe, P. Flach, S. Ross, D. Spendlove, S. Bolliger, P. Vock, M.J. Thali, Clinical radiology and postmortem imaging (Virtopsy) are not the same: Specific and unspecific postmortem signs, Leg Med (Tokyo) 12(5) (2010) 215-22.

[31] K. Yamazaki, S. Shiotani, N. Ohashi, M. Doi, K. Honda, Hepatic portal venous 
gas and hyper-dense aortic wall as postmortem computed tomography finding, Leg Med (Tokyo) 5 Suppl 1 (2003) S338-41. 


\section{Acknowledgments}

We thank Prof. Dr. Myles O’Brien (Mie Prefectural College of Nursing, Tsu, Mie, Japan) for assistance with English Language. 
Table 1

Case profiles

\begin{tabular}{|c|c|c|c|c|c|c|c|c|c|c|c|c|c|}
\hline & day 0.5 & day 1 & day 1.5 & day 2 & day 2.5 & day 3 & day 4 & day 5 & day 7 & day 10 & day 14 & day 21 & day 30 \\
\hline $\mathrm{n}$ (male:female) & $12(8: 4)$ & $17(10: 7)$ & $24(13: 11)$ & $80(53: 27)$ & $4(1: 4)$ & $22(15: 7)$ & $7(7: 0)$ & $2(1: 1)$ & $9(5: 4)$ & $4(3: 1)$ & $4(3: 1)$ & $1(1: 0)$ & $3(0: 3)$ \\
\hline age (mean) & 54.6 & 62.8 & 59.5 & 59.4 & 58.5 & 56.7 & 58.0 & 72.0 & 63.9 & 60.5 & 72.0 & 69.0 & 66.0 \\
\hline causes of death & & & & & & & & & & & & & \\
\hline drowning & 1 & 3 & 7 & 7 & 2 & 7 & 2 & 0 & 1 & 0 & 1 & 0 & 0 \\
\hline sudden cardiac death & 1 & 4 & 4 & 8 & 0 & 3 & 3 & 0 & 0 & 0 & 0 & 0 & 0 \\
\hline asphyxia & 2 & 1 & 4 & 6 & 1 & 3 & 0 & 1 & 0 & 0 & 0 & 0 & 0 \\
\hline co poisoning & 2 & 2 & 2 & 1 & 0 & 2 & 1 & 0 & 0 & 0 & 0 & 0 & 0 \\
\hline multiorgan failure & 0 & 1 & 1 & 1 & 0 & 2 & 0 & 0 & 1 & 0 & 0 & 1 & 0 \\
\hline blood loss & 3 & 1 & 1 & 0 & 0 & 0 & 0 & 0 & 0 & 0 & 0 & 0 & 0 \\
\hline sepsis & 0 & 1 & 1 & 0 & 0 & 0 & 0 & 0 & 1 & 0 & 1 & 0 & 0 \\
\hline burn & 0 & 0 & 1 & 3 & 0 & 0 & 0 & 0 & 0 & 0 & 0 & 0 & 0 \\
\hline drug poisoning & 0 & 0 & 1 & 0 & 1 & 1 & 0 & 1 & 0 & 0 & 0 & 0 & 0 \\
\hline pulmonary artery embolization & 1 & 1 & 0 & 0 & 0 & 0 & 0 & 0 & 0 & 0 & 0 & 0 & 0 \\
\hline crash syndrome & 1 & 0 & 0 & 0 & 0 & 0 & 0 & 0 & 1 & 0 & 0 & 0 & 0 \\
\hline electrocution & 1 & 0 & 0 & 1 & 0 & 0 & 0 & 0 & 0 & 0 & 0 & 0 & 0 \\
\hline peritonitis & 0 & 0 & 1 & 0 & 0 & 0 & 0 & 0 & 0 & 0 & 0 & 0 & 0 \\
\hline ketoacidosis & 0 & 0 & 0 & 1 & 0 & 0 & 0 & 0 & 0 & 0 & 0 & 0 & 0 \\
\hline cardiac tamponade & 0 & 0 & 0 & 0 & 0 & 1 & 0 & 0 & 0 & 0 & 0 & 0 & 0 \\
\hline cancer & 0 & 0 & 0 & 0 & 0 & 0 & 0 & 0 & 0 & 0 & 0 & 0 & 1 \\
\hline hanging & 0 & 0 & 0 & 0 & 0 & 1 & 0 & 0 & 0 & 0 & 0 & 0 & 0 \\
\hline brain infarction & 0 & 0 & 0 & 0 & 0 & 0 & 0 & 0 & 0 & 0 & 1 & 0 & 0 \\
\hline malnutrition & 0 & 0 & 0 & 0 & 0 & 0 & 0 & 0 & 0 & 0 & 0 & 0 & 1 \\
\hline renal failure & 0 & 0 & 0 & 0 & 0 & 0 & 1 & 0 & 0 & 0 & 0 & 0 & 0 \\
\hline unknown & 0 & 3 & 1 & 52 & 0 & 2 & 0 & 0 & 5 & 4 & 1 & 0 & 1 \\
\hline $\begin{array}{c}\text { lateral ventricle CT value } \\
\text { mean } \pm \mathrm{SD}(\mathrm{HU})\end{array}$ & $20.69 \pm 1.01$ & $18.86 \pm 0.95$ & $19.24 \pm 1.07$ & $20.34 \pm 0.95$ & $20.04 \pm 0.95$ & $21.52 \pm 0.94$ & $22.54 \pm 0.89$ & $20.14 \pm 0.90$ & $24.22 \pm 1.23$ & $26.60 \pm 1.13$ & $24.74 \pm 1.13$ & 19.450 & $27.76 \pm 0.91$ \\
\hline
\end{tabular}


Table 2

Statistical Results (Bonferroni-Dunn)

\begin{tabular}{|c|c|c|c|c|c|c|c|c|}
\hline$p$ value & day 1 & day 1.5 & day 2 & day 2.5 & day 3 & day 4 & day 5 & day 7 \\
\hline day 0.5 & 0.1970 & 0.2640 & 0.7989 & 0.5850 & 0.5390 & 0.3002 & 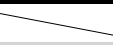 & 0.0237 \\
\hline day 1 & mand & 0.7718 & 0.1272 & 0.7567 & 0.0294 & 0.0300 & 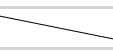 & 0.0004 \\
\hline day 1.5 & . & $m$ & 0.1746 & 0.8819 & 0.0380 & 0.0396 & - & 0.0004 \\
\hline day 2 & 2 & +2 & 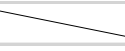 & 0.6444 & 0.2145 & 0.1477 & $m$ & 0.0024 \\
\hline day 2.5 & man & 2 & $\mathrm{~m}$ & $m$ & 0.3248 & 0.1979 & $m$ & 0.0291 \\
\hline day 3 & $x_{0}$ & 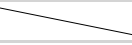 & & & - & 0.5296 & & 0.0487 \\
\hline day 4 & $m$ & $m$ & 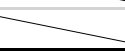 & 2 & 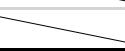 & ren & + & 0.3111 \\
\hline
\end{tabular}


Table 3

Case profiles of postmortem time-width

\begin{tabular}{|c|c|c|c|}
\hline & Group A & Group B & Group C \\
\hline n (male:female) & $137(85: 52)$ & $40(28: 12)$ & $12(7: 5)$ \\
\hline age (mean) & $23-97(59.4)$ & $23-94(60.0)$ & $39-82(63.7)$ \\
\hline postmortem time (day) & $0.5-2.5(1.7)$ & $3-7(4.2)$ & $10-30(17.3)$ \\
\hline causes of death & & & \\
\hline drowning & 20 & 10 & 1 \\
\hline sudden cardiac death & 17 & 6 & 0 \\
\hline asphyxia & 14 & 4 & 0 \\
\hline co poisoning & 7 & 3 & 0 \\
\hline multiorgan failure & 3 & 3 & 1 \\
\hline blood loss & 5 & 0 & 0 \\
\hline sepsis & 2 & 1 & 1 \\
\hline burn & 4 & 0 & 0 \\
\hline drug poisoning & 2 & 2 & 0 \\
\hline pulmonary artery embolization & 2 & 0 & 0 \\
\hline crash syndrome & 1 & 1 & 0 \\
\hline electrocution & 2 & 0 & 0 \\
\hline peritonitis & 1 & 0 & 0 \\
\hline ketoacidosis & 1 & 0 & 0 \\
\hline cardiac tamponade & 0 & 1 & 1 \\
\hline cancer & 0 & 0 & 0 \\
\hline hanging & 0 & 1 & 1 \\
\hline brain infarction & 0 & 0 & 0 \\
\hline malnutrition & 0 & 0 & 1 \\
\hline renal failure & $0.0 \pm 3.3$ & $22.0 \pm 4.2$ & $26.5 \pm 5.9$ \\
\hline UK & & & \\
\hline lateral ventricle CT value & & & 0 \\
\hline mean \pm SD (HU) & & & 0 \\
\hline
\end{tabular}


Fig. 1 Measurement of CSF CT density

The CSF densities at the lateral ventricles were measured using 3 ROIs, which excluded the choroid plexus or visible beam hardening artifact. The pixel standard deviation was also measured.

(a) 40 year-old female, death by pulmonary artery thromboembolism. 2 days postmortem (group A).

(b) 30 year-old male, death by cardiac infarction. 5 days postmortem (group B).

(c) 70 year-old female, death by starvation. 10 days postmortem (group C)

Fig. 2 CSF CT value along the postmortem time

The short postmortem period showed around $20 \mathrm{HU}$ in CSF density, and it is gradually increased along with postmortem intervals. In statistical evaluation, postmortem day 3 was the earliest increased CSF density compared to day 1 and 1.5. Day 7 presented statistically increased CSF density compared to the short postmortem period (up to 3 days).

Fig. 3 CSF CT value compared with the postmortem time-width

The CSF density shows an increase along with postmortem time-width, which is statistically significant.

Postmortem period:

Group A: up to day 2.5

Group B: day 3 to 7

Group C: beyond day 7 
Figure 1a

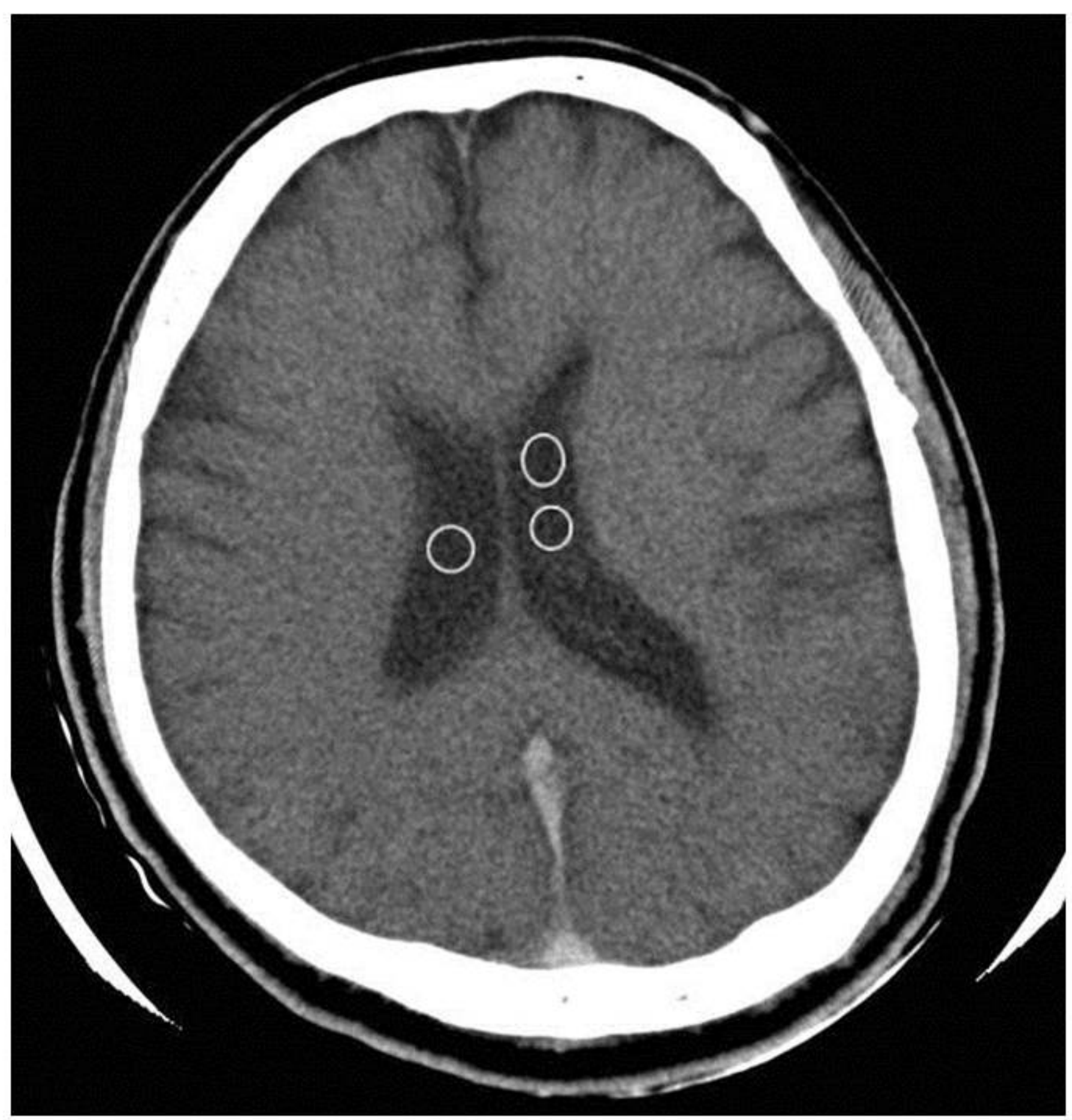




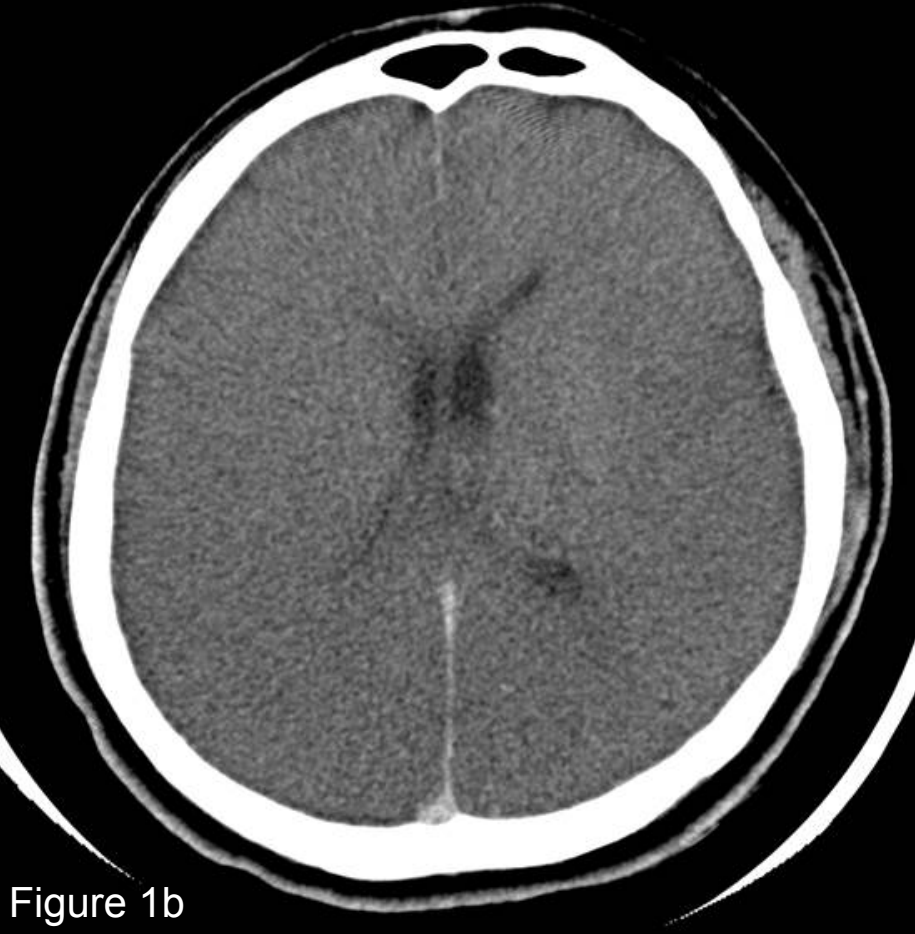




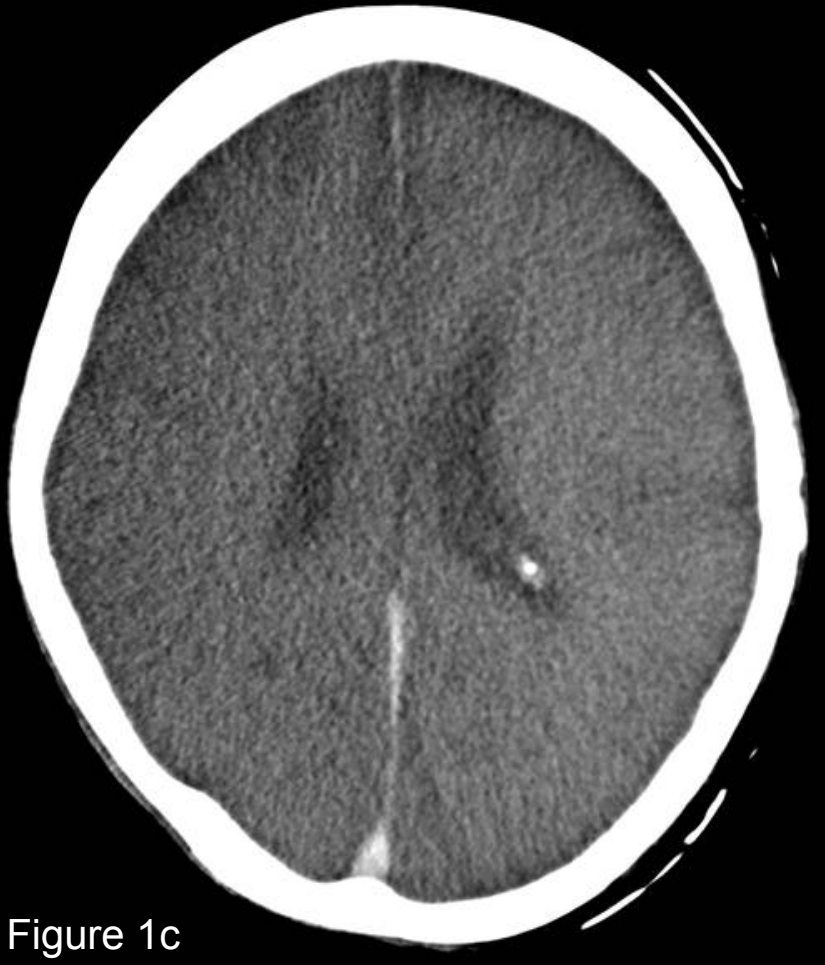




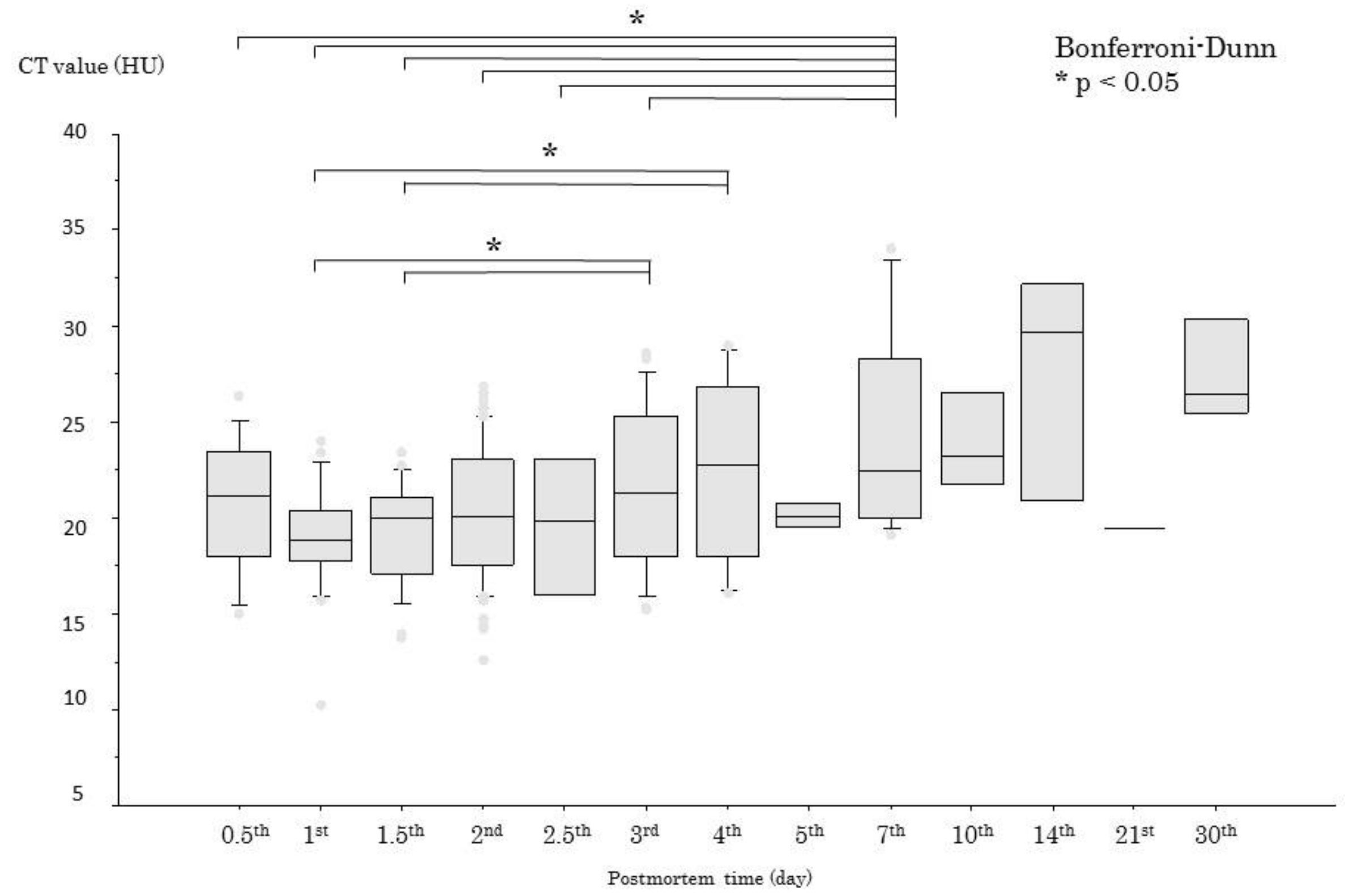

Figure 2 
$\mathrm{CT}$ value (HU)

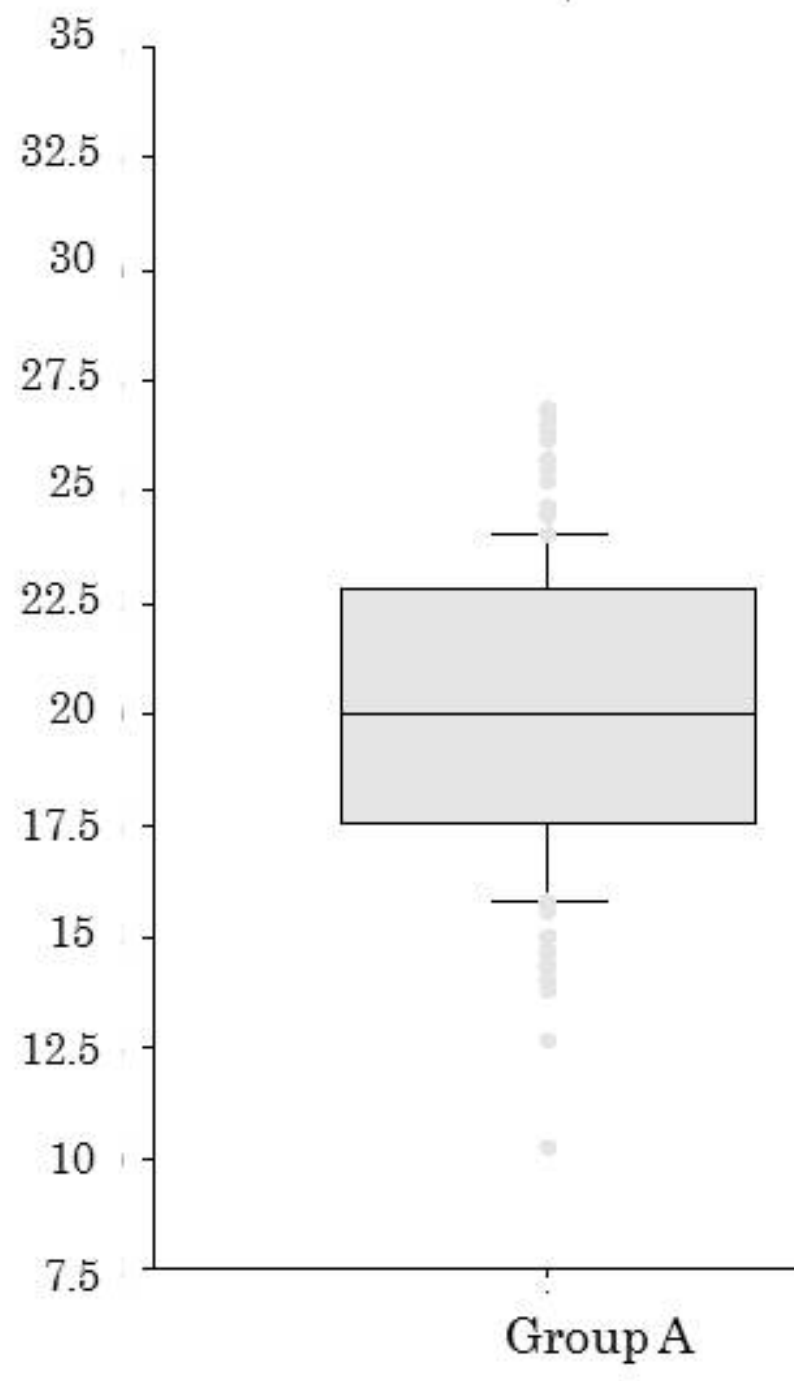

*
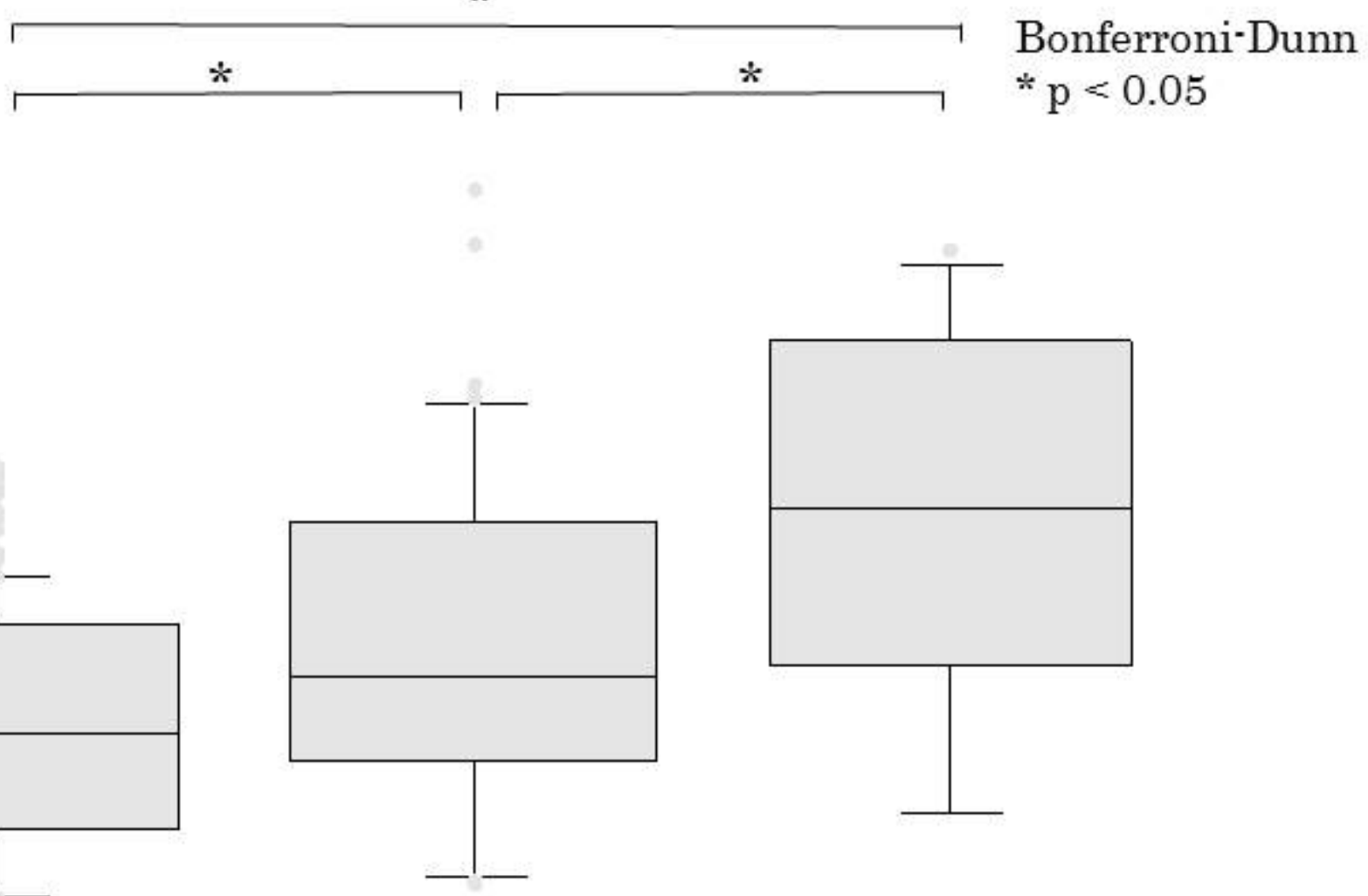

Figure 3 